Check for updates

Cite this: New J. Chem., 2019, 43,356

Received 22nd September 2018, Accepted 21st November 2018

DOI: 10.1039/c8nj04823a

rsc.li/njc

\title{
Hot injection synthesis of CulnS 2 nanocrystals using metal xanthates and their application in hybrid solar cells $\uparrow$
}

\author{
Verena Perner, ${ }^{a}$ Thomas Rath, (D) *a Franz Pirolt, ${ }^{a}$ Otto Glatter, ${ }^{a}$ Karin Wewerka, ${ }^{b}$ \\ Ilse Letofsky-Papst, ${ }^{b}$ Peter Zach, ${ }^{c}$ Mathias Hobisch, ${ }^{d}$ Birgit Kunert ${ }^{e}$ and \\ Gregor Trimmel (iD a
}

\begin{abstract}
Copper indium sulfide $\left(\mathrm{CulnS}_{2}\right)$ nanocrystals with a size of 3-4 $\mathrm{nm}$ and a chalcopyrite crystal structure were synthesized from copper and indium xanthates as precursors in a hot injection synthesis performed at a temperature of $200{ }^{\circ} \mathrm{C}$. Dioleamide molecules served as stabilizing ligands and were exchanged to 1-hexanethiol after the synthesis. TEM images reveal that after the ligand exchange process, the inter-particle distance is significantly reduced and the nanocrystals agglomerate slightly, which is also indicated by small angle X-ray scattering and AFM measurements. Information about charge transfer between the conjugated polymer PCDTBT and the nanocrystals was gained from photoluminescence quenching measurements. Furthermore, the prepared $\mathrm{CulnS}_{2}$ nanoparticles with an optical band gap of $1.57 \mathrm{eV}$ were applied as acceptors in polymer/nanocrystal bulk heterojunction solar cells and their performance was evaluated. The obtained solar cells showed high open circuit voltages up to $730 \mathrm{mV}$ and overall power conversion efficiencies of $0.23 \%$.
\end{abstract}

\section{Introduction}

Copper containing chalcogenide nanocrystals became an exciting research topic because of manifold application possibilities based on their optical and electronic properties. ${ }^{1,2}$ In addition, their properties can be further tuned through quantum confinement effects based on variations in size and shape and as well through engineering of the chemical composition and the ligand environment. ${ }^{3-9}$ Copper indium sulfide $\left(\mathrm{CuInS}_{2}\right)$ nanocrystals are particularly interesting, as they are a potential nontoxic alternative to cadmium or lead containing nanocrystals. ${ }^{1,2,10}$ Copper indium sulfide possesses a high absorption coefficient, a direct band gap of $1.5 \mathrm{eV}^{11}$ and a large Stokes shift. ${ }^{12}$ Thus CuInS 2

\footnotetext{
${ }^{a}$ Institute for Chemistry and Technology of Materials (ICTM), NAWI Graz, Graz University of Technology, Stremayrgasse 9, 8010 Graz, Austria. E-mail: thomas.rath@tugraz.at

${ }^{b}$ Institute for Electron Microscopy and Nanoanalysis and Center for Electron Microscopy, Graz University of Technology, NAWI Graz, Steyrergasse 17, 8010 Graz, Austria

${ }^{c}$ Institute of Analytical Chemistry and Food Chemistry, NAWI Graz, Graz University of Technology, Graz, Austria, Stremayrgasse 9, 8010 Graz, Austria

${ }^{d}$ Institute of Paper, Pulp and Fibre Technology, Graz University of Technology, Inffeldgasse 23, $8010 \mathrm{Graz}$, Austria

${ }^{e}$ Institute of Solid State Physics, Graz University of Technology, Petersgasse 16, 8010 Graz, Austria

$\dagger$ Electronic supplementary information (ESI) available: ${ }^{1} \mathrm{H}-\mathrm{NMR}$ spectra and additional XRD and solar cell data. See DOI: 10.1039/c8nj04823a
}

nanocrystals find applications in biolabelling, ${ }^{13,14}$ LEDs, ${ }^{15}$ photocatalysis $^{16}$ and, in particular also, photovoltaics. ${ }^{17}$ Regarding solar cell applications, $\mathrm{CuInS}_{2}$ nanocrystals are used in mesoscopic semiconductor sensitized solar cells, ${ }^{8,18,19}$ nanocrystalline thin film solar cells, ${ }^{20,21}$ and bulk heterojunction polymer/nanoparticle solar cells. $^{22-29}$

However, compared to $\mathrm{Cd}$ - or $\mathrm{Pb}$-containing sulfide or selenide nanocrystals, the application of $\mathrm{CuInS}_{2}$ nanocrystals in bulk heterojunction hybrid solar cells is less researched and the performance of $\mathrm{CuInS}_{2}$ nanocrystal based bulk heterojunction solar cells remained much lower. While power conversion efficiencies (PCEs) up to $5.5 \%$ or $6.3 \%$ are obtained with $\mathrm{PbS}$,Se nanocrystal/polymer ${ }^{30}$ or CdTe/polymer ${ }^{31}$ bulk heterojunction absorber layers, respectively, PCEs lower than $0.1 \%$ are reached with ligand exchanged CuInS ${ }_{2}$ nanocrystals in combination with a conjugated polymer. ${ }^{22-26}$ Higher efficiencies up to $2.9 \%$ were only obtained with ligand-free $\mathrm{CuInS}_{2}$ nanocrystals synthesized directly in the conjugated polymer film..$^{27,32,33}$ These results reveal that the non-toxic copper indium sulfide nanocrystals have a high potential in hybrid solar cells.

In recent years much research effort was devoted to exploring synthesis strategies and the investigation of the properties of $\mathrm{CuInS}_{2}$ nanocrystals. Synthetic approaches include colloidal synthesis routes (heat up and hot injection syntheses), ${ }^{34}$ hydrothermal and solvothermal methods ${ }^{35}$ including microwave assisted syntheses $^{36}$ as well as in situ formation in polymeric matrices. ${ }^{32}$ 
In most cases molecules such as oleylamine, ${ }^{34}$ oleic acid, octadecene, trioctylphosphine or dodecanethiol are used as ligands and copper and indium salts (e.g. halides, acetates, acetylacetonates) in combination with a sulfur source (e.g. elemental sulfur, thiourea, dodecanethiol) as precursors. ${ }^{1}$ Furthermore, single source precursors ${ }^{37,38}$ and precursors which contain the metal and sulfur source in one compound (e.g. dithiocarbamates) ${ }^{39}$ are already investigated. In this regard, also metal xanthates have been proven to be very suitable. ${ }^{40-45}$ Examples for a hot injection synthesis of $\mathrm{CuInS}_{2}$ nanoparticles comprise the syntheses from the corresponding copper and indium ethyl xanthates using glycol $^{38}$ or trioctylamine as solvent and oleylamine/trioctylphosphine as ligands. ${ }^{39}$ Alternatively, nanocrystals have been isolated via the decomposition of copper and indium xanthates in a mixture of $o$-dichlorobenzene as solvent and oleylamine/ trioctylphosphine ${ }^{40}$ or poly(3-hexylthiophene) (P3HT) as polymeric ligand. ${ }^{41}$ Furthermore, a series of xanthates with different alkyl side chains was investigated for the synthesis of $\mathrm{CuInS}_{2}$ nanocrystals with hexagonal and cubic phase by Al-Shakban et al. ${ }^{37}$ Whereas the formation to the metal sulfide proceeds via the thermally activated Chugaev reaction, the reaction pathway might change in the presence of alkyl amines as we have recently shown for a room temperature synthesis of $\mathrm{CuInS}_{2}$ nanocrystals using oleylamine. ${ }^{42}$

In this study, we focus on the synthesis of $\mathrm{CuInS}_{2}$ nanocrystals from metal xanthates using dioleamide (oleyl oleamide, $N$-((Z)-octadec-9-en-1-yl)oleamide) as capping ligand and investigate the nanocrystals as well as the ligand exchange with hexanethiol via X-ray diffraction and scattering measurements, thermogravimetric analysis, IR spectroscopy, and transmission electron microscopy. Furthermore, we evaluate the performance of the ligand-exchanged nanocrystals in polymer/nanocrystal bulk heterojunction solar cells.

\section{Experimental}

\subsection{Sample and solar cell preparation}

Materials. Copper and indium xanthates (copper O-2,2-dimethylpentan-3-yl dithiocarbonate, indium O-2,2-dimethylpentan-3-yl dithiocarbonate) were synthesized by Aglycon $\mathrm{GmbH}$ based on a published protocol ${ }^{27}$ and recrystallized from chloroform/methanol. PCDTBT (poly[[9-(1-octylnonyl)-9H-carbazole-2,7-diyl]-2,5-thiophenediyl-2,1,3-benzothiadiazole-4,7-diyl-2,5-thiophenediyl]) was purchased from 1-material. PEDOT:PSS (poly(3,4-ethylenedioxythiophene)-poly(styrenesulfonate)), Clevios P VP.Al 4083 was obtained from Heraeus, ITO-coated glass slides $\left(15 \Omega \mathrm{sq}^{-1}\right)$ from Lumtec and silver (pellets, 99.99\%) from Kurt J. Lesker Company.

Nanocrystal synthesis. A mixture of $15 \mathrm{~mL}$ oleylamine and $15 \mathrm{~mL}$ oleic acid was heated to $200{ }^{\circ} \mathrm{C}$ under inert (nitrogen) atmosphere in a three-necked flask. $191.2 \mathrm{mg}$ ( $0.75 \mathrm{mmol}, 1 \mathrm{eq}$. copper $O$-2,2-dimethylpentan-3-yl-dithiocarbonate and $1.171 \mathrm{~g}$ (1.7 mmol, 2.26 eq.) indium $O$-2,2-dimethylpentan-3-yl-dithiocarbonate were dissolved in $6.5 \mathrm{~mL}$ 1,2,4-trichlorobenzene. Subsequently, the prepared precursor solution was injected via a syringe into the hot reaction mixture, which became brownishblack immediately. After 30 minutes, the black reaction product was left to cool down to room temperature. The nanocrystals were precipitated by pouring the reaction solution into twice the amount of methanol followed by a centrifugation step (3600 rpm, $5 \mathrm{~min}$ ). After this first centrifugation step, an opaque black and a transparent colorless liquid phase were obtained. After decanting of the colourless liquid phase, the black phase was poured into a mixture of $20 \mathrm{~mL} n$-hexane and $20 \mathrm{~mL}$ ethanol followed by a second centrifugation step at $3600 \mathrm{U} \mathrm{min}^{-1}$ for $5 \mathrm{~min}$. The clear supernatant was decanted and the remaining black solid was dissolved in $8 \mathrm{~mL}$ chloroform. In a last step, the nanoparticles were precipitated again in methanol followed by centrifugation.

Ligand exchange. $150 \mathrm{mg}$ of $\mathrm{CuInS}_{2}$ nanoparticles were dissolved in $5 \mathrm{~mL}$ 1-hexanethiol and heated to $80{ }^{\circ} \mathrm{C}$. After 24 hours, the solution was cooled down to room temperature and the black-brown nanoparticle solution was poured into ethanol : acetone $=1: 1$ (volume ratio of $10: 1$ with regard to the ligand exchange solution). The nanoparticles were separated by centrifugation. The brownish supernatant was decanted and the remaining nanoparticles were dissolved in chloroform resulting in a black-brown solution.

Thin film and solar cell preparation. Patterned ITO-coated glass slides $(15 \times 15 \mathrm{~mm})$ were rinsed with acetone followed by a cleaning step in isopropanol in an ultrasonic bath and an $\mathrm{O}_{2}$ plasma cleaning step (FEMTO, Diener Electronic, Germany). Next, the PEDOT:PSS hole extraction layer was spin coated (2500 rpm, $30 \mathrm{~s})$ on the substrates and subsequently heated to $150{ }^{\circ} \mathrm{C}$ for $10 \mathrm{~min}$ in a nitrogen filled glove box (resulting layer thickness: $40 \mathrm{~nm}$ ). The aqueous PEDOT:PSS suspension was filtered through a $0.45 \mu \mathrm{m}$ PVDF filter (Chromafil Xtra) before spin coating. PCDTBT was dissolved in chlorobenzene at a concentration of $5 \mathrm{mg} \mathrm{mL}^{-1}$. The solution was stirred at $70{ }^{\circ} \mathrm{C}$ for one hour. The ligand-exchanged $\mathrm{CuInS}_{2}$ nanoparticles were dissolved in the polymer solution in polymer to $\mathrm{CuInS}_{2}$ weight ratios of $1: 5,1: 9$ and $1: 15$. The PCDTBT/CuInS P $_{2}$ absorber layers were spin coated at a speed of $1500 \mathrm{rpm}$. Finally, 80-90 nm thick silver cathodes were deposited in a vacuum chamber $\left(8 \times 10^{-6}\right.$ mbar $)$ via thermal evaporation through a shadow mask. The active area of the devices was $0.09 \mathrm{~cm}^{2}$.

\subsection{Characterisation techniques}

X-ray diffraction measurements were conducted on a PANalytical Empyrean diffractometer in Bragg-Brentano configuration operated at $40 \mathrm{kV}$ and $40 \mathrm{~mA}$ using $\mathrm{Cu} \mathrm{K}_{\alpha}$ radiation. UV-Vis absorption spectra were measured on a Shimadzu 1800 spectrophotometer. Thermogravimetric analyses (TGA) were performed on a Netzsch Jupiter STA 449C. All measurements were carried out in helium atmosphere and at a heating rate of $10{ }^{\circ} \mathrm{C} \mathrm{min}^{-1}$ from room temperature to $550{ }^{\circ} \mathrm{C}$. FT-IR spectra were acquired using a Bruker Alpha FT-IR spectrometer in attenuated total reflection (ATR) mode (films on glass substrates, spectral range between 4000 and $400 \mathrm{~cm}^{-1}$ ). ${ }^{1} \mathrm{H}$-NMR spectroscopy was carried out on a Bruker Avance $300 \mathrm{MHz}$ spectrometer. $\mathrm{CDCl}_{3}$ was obtained from Cambridge Isotope Laboratories Inc.

For transmission electron microscopy (TEM), samples were prepared by dropping a nanoparticle solution (solvent: chloroform) onto a Quantifoil TEM-grid with a carbon film and subsequent 
evaporation of the solvent at room temperature. TEM images were acquired on a Tecnai F20 microscope (FEI company) at $200 \mathrm{kV}$ acceleration voltage, equipped with a Schottky emitter, an energy dispersive X-ray spectrometer, a monochromator and a Gatan Image Filter (GIF) with an UltraScanCCD camera.

The Small Angle X-Ray Scattering (SAXS) equipment consisted of a high-flux SAXSess camera (Anton Paar, Austria) connected to a Debyeflex 3003 X-ray generator (GE-Electric, Germany), operating at $40 \mathrm{kV}$ and $50 \mathrm{~mA}$ with a sealed-tube $\mathrm{Cu}$ anode. The Goebel-mirror focused and Kratky-slit collimated X-ray beam was line shaped $(17 \mathrm{~mm}$ horizontal dimension at the sample). The scattered radiation was measured in transmission mode and recorded by a one-dimensional MYTHEN-1k microstrip solid-state detector (Dectris, Switzerland) within a $q$-range (with $q$ being the magnitude of the scattering vector) of 0.01 to $0.5 \AA^{-1}$. Using $\mathrm{Cu} \mathrm{K}_{\alpha}$ radiation of a wavelength of $1.54 \AA$ and a sample-to-detector distance of $307 \mathrm{~mm}$, this corresponds to a total $2 \theta$ region of $0.14^{\circ}$ to $7^{\circ}$, applying the conversion $q=$ $4 \pi(\sin \theta) / \lambda$ with $2 \theta$ being the scattering angle with respect to the incident beam and $\lambda$ the wavelength of the X-rays. Capillaries of $1.0 \mathrm{~mm}$ diameter were used and the exposure was set to $60 \mathrm{~s}$ and repeated 5 times. The alignment of the apparatus allowed a resolution of $47.24 \mathrm{~nm}$ diameter $\left(q_{\min }=0.0665 \mathrm{~nm}^{-1}\right) .90 \%$ of the toluene curve was subtracted from the sample files and the resulting curves were binned to decrease the amount of data points. The treated data files were evaluated using the Indirect Fourier Transformation Method. ${ }^{46}$

Photoluminescence spectra were measured in ambient atmosphere on a FluoroLog 3 spectrofluorometer from Horiba Scientific equipped with a NIR-sensitive R2658 photomultiplier from Hamamatsu (300-1050 nm). The PL spectra were corrected for the spectral sensitivity of the detector.

$J V$ curves of the solar cells were recorded in a glovebox using a Keithley 2400 source measure unit and a custom made LabView software. The samples were illuminated by a Dedolight lamp with a spectrum similar to the AM $1.5 \mathrm{G}$ spectrum at $100 \mathrm{~mW} \mathrm{~cm} \mathrm{~cm}^{-2}$. The intensity was calibrated with a Fraunhofer silicon reference solar cell. Layer thicknesses were measured using a Bruker Dektak XT surface profiler.

Atomic Force Microscopy (AFM) measurements were performed on a Veeco Multimode Quadrax MM atomic force microscope (Bruker) in tapping mode using non-coated Si-cantilevers (NCH-VS1-W, NanoWorld AG) with a resonance frequency of $291 \mathrm{kHz}$ and a force constant of $42 \mathrm{~N} \mathrm{~m}^{-1}$. The measurements were acquired at room temperature under ambient conditions. All calculations and image processing was done with Nanoscope software (V7.30r1sr3, Veeco).

\section{Results and discussion}

The $\mathrm{CuInS}_{2}$ nanocrystals were prepared via the hot-injection method using copper and indium xanthates as precursors. These precursors are known to decompose rapidly at a temperature of approx. $130{ }^{\circ} \mathrm{C}^{27}$ Therefore, the reactions were carried out in trichlorobenzene as solvent, which has a sufficiently high boiling point to conduct the synthesis at $200{ }^{\circ} \mathrm{C}$. Regarding the choice of capping ligands, preliminary hot-injection experiments have shown that mixtures of oleic acid and oleylamine gave better results than experiments using solely oleylamine or oleic acid. In the latter case larger precipitates were observed, which were insoluble after the precipitation (primary crystallite size according to Scherrer equation: $16 \mathrm{~nm}$; the X-ray diffraction pattern is shown in Fig. S1, ESI $\dagger$ ). When only oleylamine was used as capping ligand, despite the good results we obtained in a room temperature synthesis, ${ }^{42}$ extremely small nanocrystals were synthesized, which could not be precipitated and separated from the reaction solution. However, by using a 1:1 mixture of oleylamine and oleic acid, dioleamide is formed directly in the reaction solution during the pre-heating phase, acting then as ligand during the nanoparticle synthesis. This dioleamide formation was already observed by D. G. Calatayud et al. ${ }^{47}$ and was also confirmed by ${ }^{1} \mathrm{H}-\mathrm{NMR}$ spectroscopy (see ESI, $\dagger$ Fig. S2). After the preheating phase, the solution of copper and indium xanthates was swiftly injected into the solution of dioleamide in trichlorobenzene at $200{ }^{\circ} \mathrm{C}$ and the reaction solution was held at this temperature for $30 \mathrm{~min}$ before the nanoparticles were isolated by several precipitation steps (Fig. 1).

The X-ray diffraction pattern of the prepared $\mathrm{CuInS}_{2}$ nanocrystals is depicted in Fig. 2A and shows broad peaks at 28.0 (112), 46.6 (220), 55.0 (116/312) and $75^{\circ} 2 \theta$ (316/322), which match well with the reference pattern of chalcopyrite $\mathrm{CuInS}_{2}$ (PDF 01-75-0208). From the broadening of the peaks and using Scherrer equation, an instrumental broadening of $0.12^{\circ} 2 \theta$ and a Scherrer form factor of 0.9 (for spherical particles), an average primary crystallite size of $3.6 \mathrm{~nm}$ is estimated.

The UV-Vis absorption spectrum of the nanoparticles dissolved in chloroform shows the typical shape of $\mathrm{CuInS}_{2}$ nanocrystals $^{10,12,48}$ and reveals an absorption onset at $830 \mathrm{~nm}$, which corresponds to an optical band gap of $1.57 \mathrm{eV}$.

For the application of the $\mathrm{CuInS}_{2}$ nanocrystals in solar cells, the nature of the capping ligands is essential, as these critically influence properties such as solubility of the nanocrystals, wettability of the nanocrystal solutions as well as the interface between the nanocrystals in quantum dot sensitized solar cells or the interface of the nanocrystals and the conjugated polymer in polymer/nanocrystal hybrid solar cells. Thiols are known as good capping ligands for many metal sulfide nanocrystals. Thus, in this work, the bulky dioleamide ligands were exchanged with 1-hexanethiol by stirring the dioleamide stabilized nanocrystals in 1-hexanethiol at $80{ }^{\circ} \mathrm{C}$ for $24 \mathrm{~h}$. After the ligand exchange, the solubility of the nanocrystals in toluene, chloroform and chlorobenzene is slightly reduced.

To evaluate the efficiency of the ligand exchange and to determine the amount of capping ligand present in the nanocrystal samples before and after ligand exchange, thermogravimetric analysis was performed. The TGA traces of a sample before and after ligand exchange with 1-hexanethiol are presented in Fig. 3A. The mass loss of the nanocrystal sample is reduced from $32.2 \%$ before ligand exchange to $17.1 \%$ after the ligand exchange process. Moreover, for the sample before ligand exchange, a one-step decomposition with an onset ( $5 \%$ mass loss) at $310{ }^{\circ} \mathrm{C}$ 


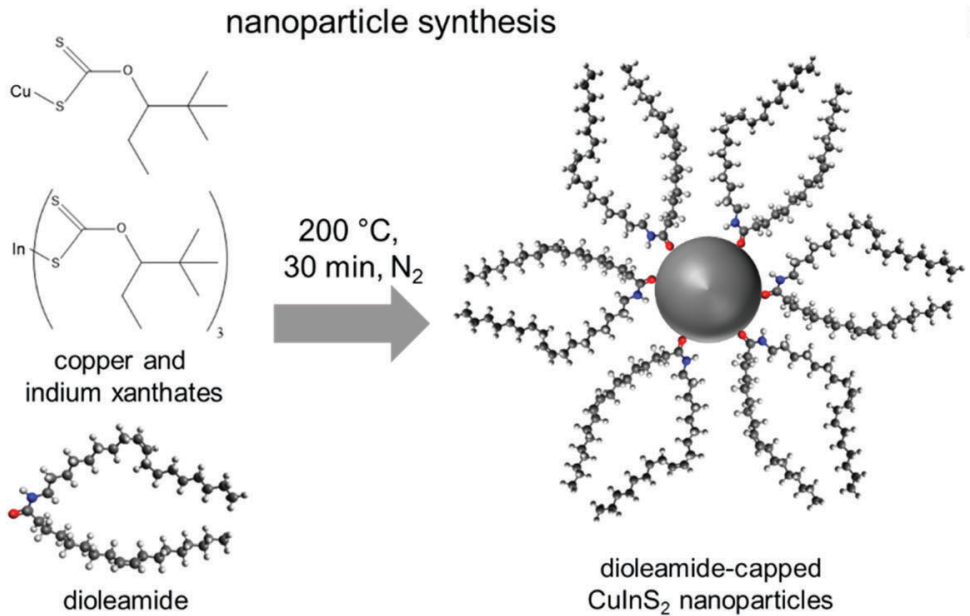

ligand exchange

$85^{\circ} \mathrm{C}, 24 \mathrm{~h}$

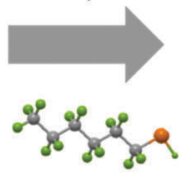

1-hexanethiol

dioleamide-capped

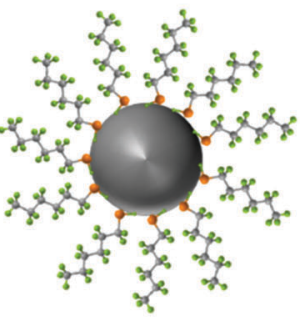

ligand exchanged CulnS $_{2}$ nanoparticles

Fig. 1 Scheme of the nanoparticle synthesis and ligand exchange with 1-hexanethiol.
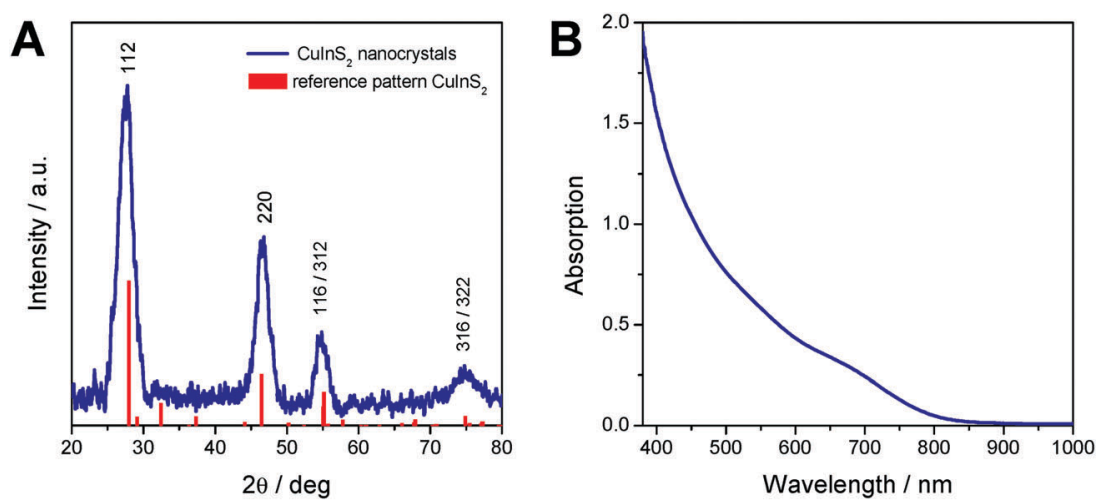

Fig. 2 (A) X-ray diffraction pattern and (B) UV-Vis spectrum of the prepared CulnS $_{2}$ nanocrystals.

was observed. This mass loss stems most likely from the decomposition of the dioleamide. The mass loss of the ligand exchanged sample displays a 2-step mass loss with onsets at $200{ }^{\circ} \mathrm{C}$ and $310{ }^{\circ} \mathrm{C}$. We assume that this first mass loss stems from the evaporation or decomposition of hexanethiol followed by the decomposition of remaining dioleamide in the second mass loss step. Based on these measurements, we can conclude that a major part of the dioleamide ligands has been removed or exchanged by 1-hexanethiol, however, a minor part is still present in the nanocrystal sample.

Moreover, the ligand exchange was characterized by FT-IR spectroscopy, which confirms the results from the TGA analysis. The IR spectra of the nanocrystals before and after ligand exchange and of pristine 1-hexanethiol are shown in Fig. 3B.
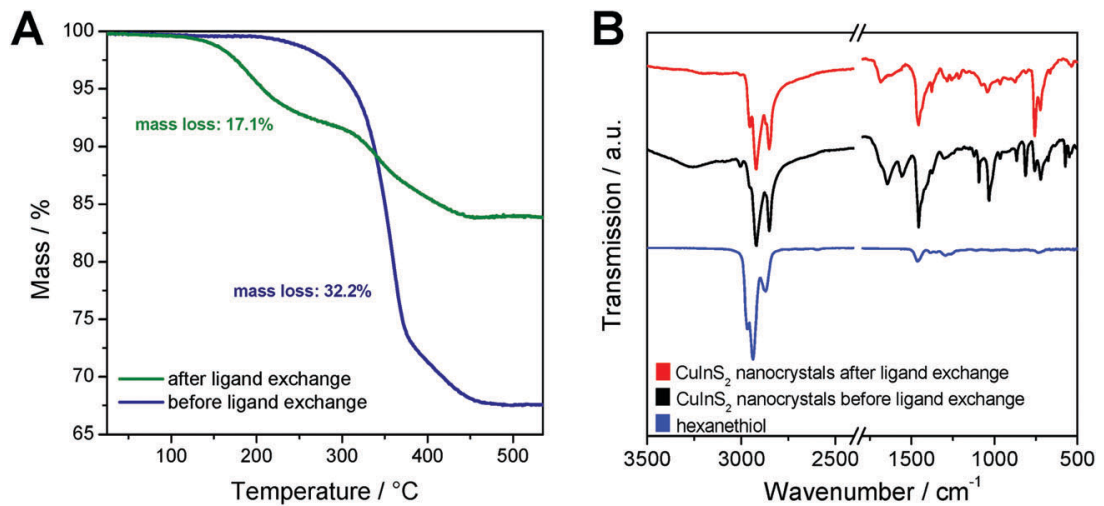

Fig. 3 (A) Thermogravimetric analysis of non-ligand exchanged and ligand exchanged nanoparticle samples; (B) FT-IR spectra of 1-hexanethiol and the CulnS $_{2}$ nanoparticle sample before and after ligand exchange. 
In the spectrum of the non-ligand exchanged nanocrystals, distinct bands at 1558 and $1644 \mathrm{~cm}^{-1}$ are visible, which correspond to the bending vibration of the $\mathrm{N}-\mathrm{H}$ bond and to the stretching vibration of the $\mathrm{C}=\mathrm{O}$ bond, respectively. The band at $1644 \mathrm{~cm}^{-1}$ can also be ascribed to the bending vibration of the $\mathrm{C}=\mathrm{C}$ bonds. Additionally, there are bands at $3005 \mathrm{~cm}^{-1}$ (overtone of amide II band) and at around $3260 \mathrm{~cm}^{-1}$ (stretching vibration of the $\mathrm{N}-\mathrm{H}$ group) observable. All these bands, which can be attributed to dioleamide, are significantly reduced in the spectrum of the ligand-exchanged $\mathrm{CuInS}_{2}$ nanocrystals.

The bands at 1458, 2852, 2921 and $2954 \mathrm{~cm}^{-1}$ are visible in both nanocrystal samples and correspond to the scissor vibration of the $\mathrm{C}-\mathrm{H}$-bond and the asymmetric and symmetric stretching vibration of the $\mathrm{C}-\mathrm{H}$ bond. Due to the aliphatic structure of dioleamide and 1-hexanethiol, these two ligands cannot be unambiguously distinguished based on these bands.
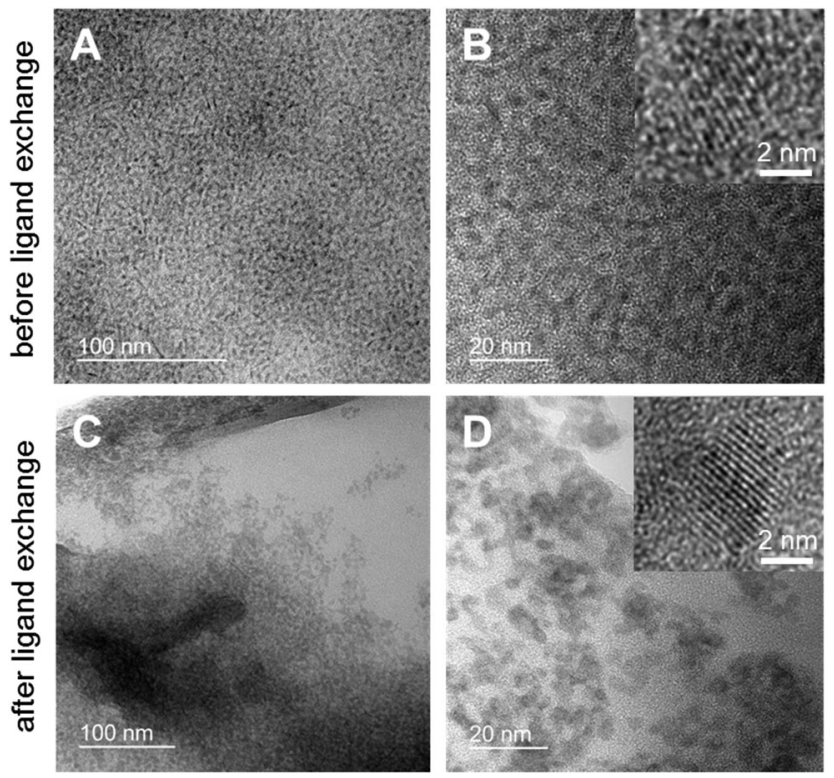

Fig. 4 TEM images of the nanoparticles in different magnifications before $(A$ and $B)$ and after ligand exchange $(C$ and $D)$.
The bands corresponding to the aliphatic bonds in the IR spectrum of pristine 1-hexanethiol are shifted to slightly lower wavenumbers when hexanethiol is coordinated to the $\mathrm{CuInS}_{2}$ nanocrystals, which can be clearly seen in Fig. 3B. The unique band for 1-hexanethiol at $2594 \mathrm{~cm}^{-1}$, which corresponds to the stretching vibration of the $\mathrm{S}-\mathrm{H}$ bond is only of weak intensity and is not observable in the ligand-exchanged nanocrystal sample. ${ }^{49}$

Furthermore, the size, shape and agglomeration behavior of the $\mathrm{CuInS}_{2}$ nanocrystals before and after the ligand exchange process were examined by transmission electron microscopy (TEM). Fig. 4 shows TEM images of the nanocrystal samples in different magnifications. It can be seen in Fig. 4A and $\mathrm{B}$ that the non-ligand exchanged nanoparticles are well separated and homogeneously distributed over the TEM grid with a certain distance between the nanoparticles. After the ligand exchange with hexanethiol, the inter-particle distance decreases significantly and they tend to agglomerate (see Fig. 4C and D). The nanocrystals have an average diameter of approx. 3-4 $\mathrm{nm}$ with a comparably narrow particle size distribution and show a globular shape. In the high resolution images (insets in Fig. 4B and D) lattice fringes are visible and an interplanar distance of $0.32 \mathrm{~nm}$ is observed, which corresponds to the spacing distance of the (112) planes of the chalcopyrite crystal structure.

In Fig. 5A, the SAXS curves of the $\mathrm{CuInS}_{2}$ nanocrystals dissolved in toluene are depicted. The SAXS data exhibit a slight upturn at low $q$ values $\left(q<0.5 \mathrm{~nm}^{-1}\right)$, which indicates the presence of larger particles, such as aggregates or agglomerates in the sample. Therefore, a polydispersity analysis was performed resulting in size distributions weighted by volume $\left(D_{\mathrm{v}}(r)\right)$, see Fig. 5B. The particle size distribution weighted by volume reveals that the majority of the samples consist of populations of primary particles of around $3 \mathrm{~nm}$ in diameter. In addition, the presence of small amounts of larger aggregates with a size of approx. $12 \mathrm{~nm}$ is visible in the particle size distribution. Moreover, as already seen in the TEM images, the size distribution of the primary nanocrystals stays constant during the ligand exchange process, however, the size distributions of the nanoparticle aggregates changes slightly.
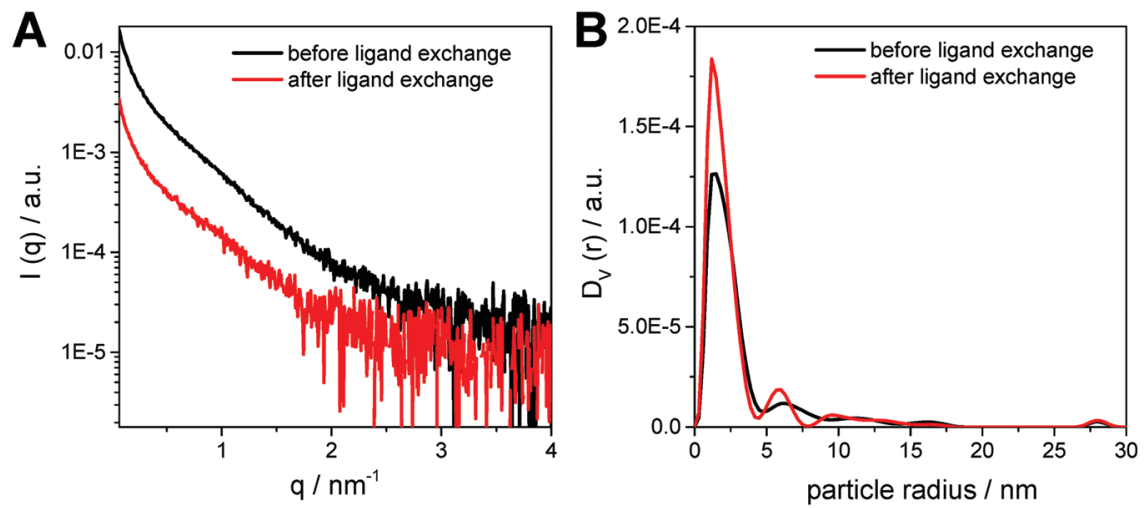

Fig. 5 (A) SAXS curves and (B) the corresponding particle size distributions weighted by volume for the nanoparticle samples before and after ligand exchange. 
In a next step, the ligand exchanged $\mathrm{CuInS}_{2}$ nanocrystals were applied in polymer/nanocrystal hybrid solar cells using PCDTBT as polymer component. The choice of polymer is based on our previous studies with in situ prepared $\mathrm{CuInS}_{2}$ nanocrystals showing that PCDTBT or PSiF-DBT led to the best device performances. ${ }^{27,33}$ PCDTBT has a LUMO level of $-3.6 \mathrm{eV}^{50}$ and the conduction band of $\mathrm{CuInS}_{2}$ nanocrystals lies slightly deeper at approx. -3.9 to $-4.0 \mathrm{eV}$ (see also Fig. S3, ESI $\dagger$ ). ${ }^{24,51}$ This makes the $\mathrm{CuInS}_{2}$ nanocrystals a well suited electron acceptor in this material combination. To obtain information about possible electron transfer from the conjugated polymer to the nanocrystals, photoluminescence (PL) quenching measurements were conducted. Fig. 6A shows the PL spectrum of a pristine PCDTBT film and PCDTBT nanocomposite films with polymer/CuInS weight ratios of $1: 5,1: 9$ and $1: 15$. The conjugated polymer shows a photoemission peak with a maximum at $725 \mathrm{~nm}$ and for the polymer/CuInS ${ }_{2}$ sample with a weight ratio of $1: 5$, this photoemission is already quenched to about $46 \%$ of its initial value. For the polymer/nanoparticle films with increased $\mathrm{CuInS}_{2}$ nanocrystal content $(1: 9, \mathrm{w}: \mathrm{w})$ the photoluminescence is decreased to $22 \%$ where it remains almost unchanged when going to higher polymer/CuInS ${ }_{2}$ ratios (see Fig. 6B). From these data it is apparent that the PL quenching is not as efficient as for nanocomposite layers containing $\mathrm{CuInS}_{2}$ nanocrystals prepared in situ in the conjugated polymer matrix. ${ }^{27,52,53}$ A possible reason for the non-complete quenching of the photoluminescence of the polymer in the films might be polymer domains in the nanocomposite layer in which the polymer is not well blended with the $\mathrm{CuInS}_{2}$ nanocrystals. ${ }^{46}$ This assumption is corroborated by the AFM images (see Fig. 7), which reveal a significant increase of roughness in the PCDTBT/CuInS ${ }_{2}$ absorber layer compared to the pristine polymer film. The increased roughness stems most probably from a partial agglomeration of the ligand exchanged nanocrystals. This leads in turn also to polymer domains which are not well mixed with the $\mathrm{CuInS}_{2}$ nanocrystals. The phase image also indicates phase separation, however, at least at the surface of the film, the phase separation is much finer as would be expected based on the topographic AFM measurements.

Furthermore, to investigate the photovoltaic properties of the hybrid layers, we prepared solar cells in the architecture
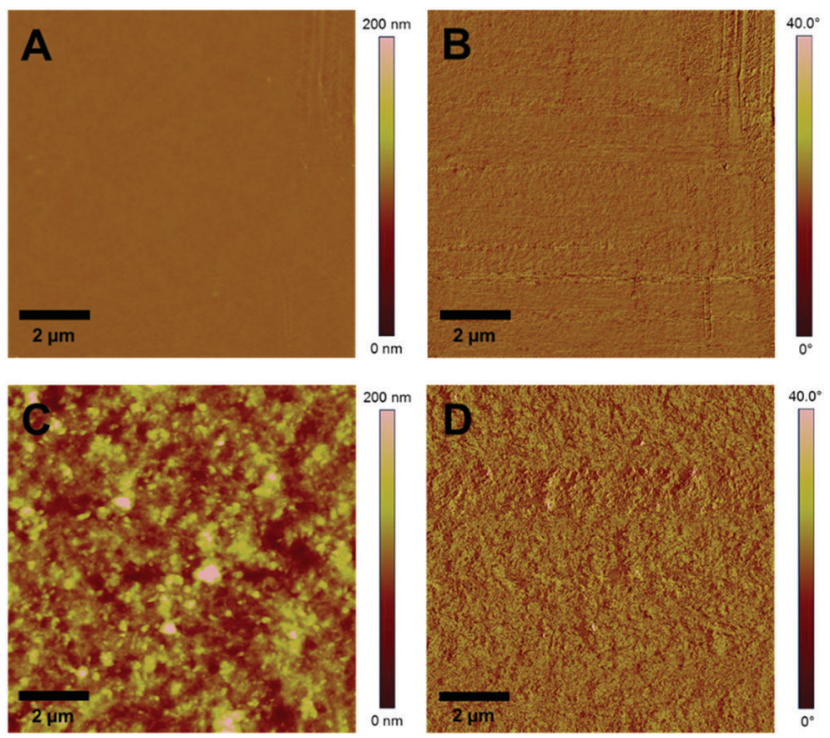

Fig. 7 AFM images of a pristine PCDTBT film and a PCDTBT/CulnS 2 (1/9, $\mathrm{w} / \mathrm{w}$ ) nanocomposite film ( $A$ and $C$ : topography images, $B$ and $D$ : phase images).

glass/ITO/PEDOT:PSS/PCDTBT-CuInS $2 /$ Ag (see Fig. 6C) with the ligand exchanged nanoparticles. The thickness of the hybrid absorber layer was 90-100 $\mathrm{nm}$. In addition, we intended to prepare solar cells with non-ligand exchanged $\mathrm{CuInS}_{2}$ nanocrystals to gain additional information about the influence of the ligand exchange on the solar cell performance. However, the polymer/nanoparticle solution did not wet the PEDOT:PSS layer resulting in very poor film quality and only partial coverage of the PEDOT:PSS layer with the absorber layer, which impeded the fabrication of solar cells with the non-ligand exchanged nanocrystals.

The $J V$ characteristics of typical solar cells prepared using the ligand exchanged nanoparticles with different polymer/nanoparticle weight ratios are presented in Fig. 6D and Fig. S4 (ESI $\dagger$ ). For the solar cells with weight ratios of $1: 5$ and $1: 15$, the PCEs remained far below $0.1 \%$. We assume that the low performance of the devices with a weight ratio of $1: 5$ is due to a too low amount of nanocrystals in the hybrid films leading to less charge
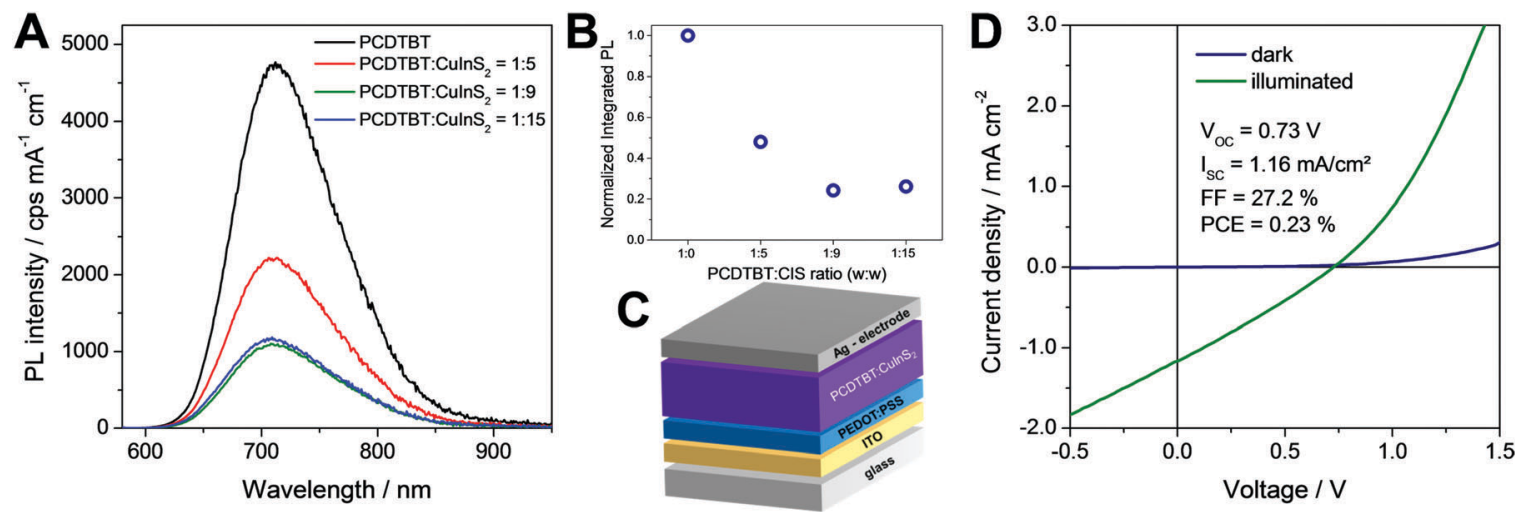

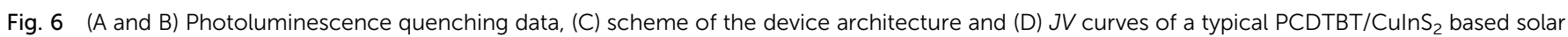
cell with a polymer/nanoparticle weight ratio of $1: 9$ in the dark and under $100 \mathrm{~mW} \mathrm{~cm}^{-2}$ illumination. 
Table 1 Characteristic parameters of the prepared PCDTBT/CulnS 2 based hybrid solar cells with a polymer/nanoparticle weight ratio of $1: 9$. The average values and standard deviations were calculated from the five best devices

\begin{tabular}{llll}
\hline$V_{\mathrm{OC}} / \mathrm{mV}$ & $I_{\mathrm{SC}} / \mathrm{mA} \mathrm{cm}^{-2}$ & $\mathrm{FF}$ & $\mathrm{PCE} / \%$ \\
\hline $0.716 \pm 0.035$ & $1.09 \pm 0.07$ & $0.27 \pm 0.01$ & $0.21 \pm 0.02$
\end{tabular}

generation, inefficient electron transport in the nanocrystal phase and in turn to a low $J_{\mathrm{Sc}}$. The films with a weight ratio of 1:15 appeared very rough and inhomogeneous, leading most likely to a partial short circuiting of the device.

In contrast to that, the solar cells with a polymer/nanocrystal weight ratio of $1: 9$ exhibited PCEs of up to $0.23 \%$. The open circuit voltage was at $730 \mathrm{mV}$, which is significantly higher than the $V_{\mathrm{OC}}$ values, which can be reached with solar cells based on absorber layers with in situ prepared ligand-free $\mathrm{CuInS}_{2}$ nanocrystals in the conjugated polymer (typical values up to $540 \mathrm{mV}){ }^{27,33}$ However, the $J_{\mathrm{SC}}\left(1.16 \mathrm{~mA} \mathrm{~cm}{ }^{-2}\right)$ and the FF $(27.2 \%)$ remained low. This is most likely due to the remaining ligands on the $\mathrm{CuInS}_{2}$ nanocrystals, the agglomeration of the nanocrystals or the rough interface between the absorber layer and the metal electrode. The average values and standard deviation of the five best solar cells prepared in this study are given in Table 1. Annealing of the absorber layer after spin coating did not positively affect the solar cell performance. Typically, the PCE values were slightly reduced when an annealing step was applied (see Fig. S5, ESI $\dagger$ ).

Even though these devices cannot compete with the PCEs of in situ prepared polymer/CuInS 2 solar cells, they are more efficient than polymer/CuInS ${ }_{2}$ hybrid solar cells reported with separately synthesized $\mathrm{CuInS}_{2}$ nanoparticles so far. ${ }^{22,23,25,29}$ The highest PCE reported in previous studies is $0.08 \%$ and was obtained with $\mathrm{P} 3 \mathrm{HT} / \mathrm{CuInS}_{2}$ hybrid solar cells. ${ }^{29}$

\section{Conclusions}

In summary, the investigated hot injection synthesis route using copper and indium xanthates as precursors and dioleamide as capping ligands leads to comparably small $\mathrm{CuInS}_{2}$ nanocrystals with sizes of only $3-4 \mathrm{~nm}$. The nanocrystals are well soluble in solvents such as chloroform, toluene and chlorobenzene. As expected, after ligand exchange with 1-hexanethiol, the solubility of the nanocrystals is slightly reduced. Thermogravimetric analyses revealed that after ligand exchange $17 \mathrm{wt} \%$ of the overall sample mass is remaining capping ligand and FT-IR measurements indicate that the majority of the dioleamide ligands are removed and exchanged to hexanethiol during the ligand exchange process. TEM images illustrate that the distance between the nanoparticles is significantly smaller after the ligand exchange and slight agglomeration of the nanocrystals is observed. In addition, SAXS measurements confirmed the size of the nanocrystals found in the TEM images. Moreover, the nanocrystals were implemented into the absorber layer of polymer/nanocrystal hybrid solar cells. It was found that these devices showed higher photovoltage compared to in situ (ligand-free) prepared polymer/CuInS ${ }_{2}$ hybrid solar cells, however, the photocurrent remained significantly lower. With the ligand exchanged nanocrystals, solar cells with PCEs of $0.23 \%$ were obtained. Even though the PCEs generally remained low, they are considerably higher compared to other polymer/ $\mathrm{CuInS}_{2}$ hybrid solar cells with separately synthesized $\mathrm{CuInS}_{2}$ nanoparticles reported before.

\section{Conflicts of interest}

There are no conflicts of interest to declare.

\section{Acknowledgements}

The authors thank Josefine Hobisch for performing the TGA analyses and Manuel Hollauf for assistance with the NMR measurements.

\section{References}

1 C. Coughlan, M. Ibáñez, O. Dobrozhan, A. Singh, A. Cabot and K. M. Ryan, Chem. Rev., 2017, 117, 5865-6109.

2 W. van der Stam, A. C. Berends and C. de Mello Donega, ChemPhysChem, 2016, 17, 559-581.

3 Y. Min, G. D. Moon, C.-E. Kim, J.-H. Lee, H. Yang, A. Soon and U. Jeong, J. Mater. Chem. C, 2014, 2, 6222-6248.

4 J. Jie, W. Zhang, I. Bello, C.-S. Lee and S.-T. Lee, Nano Today, 2010, 5, 313-336.

5 S. V. Kershaw, A. S. Susha and A. L. Rogach, Chem. Soc. Rev., 2013, 42, 3033-3087.

6 D. Aldakov, A. Lefrançois and P. Reiss, J. Mater. Chem. C, 2013, 1, 3756-3776.

7 M. V. Kolvalenko, L. Manna, A. Cabot, Z. Hens, D. V. Talapin, C. R. Kagan, V. I. Klimov, A. L. Rogach, P. Reiss, D. J. Milliron, P. Guyot-Sionnest, G. Konstantatos, W. J. Parak, T. Hyeon, B. A. Korgel, C. B. Murray and W. Heiss, ACS Nano, 2015, 9, 1012-1057.

8 D. H. Jara, S. J. Yoon, K. G. Stamplecoskie and P. V. Kamat, Chem. Mater., 2014, 26, 7221-7228.

9 S. Shen and Q. Wang, Chem. Mater., 2013, 25, 1166-1178.

10 J. Kolny-Olesiak and H. Weller, ACS Appl. Mater. Interfaces, 2013, 5, 12221-12237.

11 B. Tell, J. L. Shay and H. M. Kasper, Phys. Rev. B: Solid State, 1971, 4, 2463.

12 A. D. P. Leach and J. E. Macdonald, J. Phys. Chem. Lett., 2016, 7, 572-583.

13 C. Zhao, Z. Bai, X. Liu, Y. Zhang, B. Zou and H. Zhong, ACS Appl. Mater. Interfaces, 2015, 7, 17623-17629.

14 K. Yu, P. Ng, J. Ouyang, M. B. Zaman, A. Abulrob, T. N. Baral, D. Fatehi, Z. J. Jakubek, D. Kingston, X. Wu, X. Liu, C. Hebert, D. M. Leek and D. M. Whitfield, ACS Appl. Mater. Interfaces, 2013, 5, 2870-2880.

15 Z. Bai, W. Ji, D. Han, L. Chen, B. Chen, H. Shen, B. Zhou and H. Zhong, Chem. Mater., 2016, 28, 1085-1091.

16 S. Khanchandani, S. Kumar and A. K. Ganguli, ACS Sustainable Chem. Eng., 2016, 4, 1487-1499. 
17 O. Stroyuk, A. Raevskaya and N. Gaponik, Chem. Soc. Rev., 2018, 47, 5354-5422.

18 Z. Pan, I. Mora-Seró, Q. Shen, H. Zhang, Y. Li, K. Zhao, J. Wang, X. Zhong and J. Bisquert, J. Am. Chem. Soc., 2014, 136, 9203-9210.

19 N. Guijarro, E. Guillén, T. Lana-Villarreal and R. Gómez, Phys. Chem. Chem. Phys., 2014, 16, 9115-9122.

20 J. E. Halpert, F. S. F. Morgenstern, B. Ehrler, Y. Vaynzof, D. Credgington and N. C. Greenham, ACS Nano, 2015, 9, 5857-5867.

21 L. Li, N. Coates and D. Moses, J. Am. Chem. Soc., 2010, 132, 22-23.

22 N. Radychev, D. Scheunemann, M. Kruszynska, K. Frevert, R. Miranti, J. Kolny-Olesiak, H. Borchert and J. Parisi, Org. Electron., 2012, 13, 3154-3164.

23 C. Krause, R. Miranti, F. Witt, J. Neumann, D. Fenske, J. Parisi and H. Borchert, Sol. Energy Mater. Sol. Cells, 2014, 124, 241-246.

24 E. Arici, N. Sariciftci and D. Meissner, Adv. Funct. Mater., 2003, 13, 165-171.

25 W. Yue, S. Han, R. Peng, W. Shen, H. Geng, F. Wu, S. Tao and M. Wang, J. Mater. Chem., 2010, 20, 7570-7578.

26 S. Jindal and S. M. Giripunje, Mater. Res. Express, 2017, 4, 115506.

27 T. Rath, M. Edler, W. Haas, A. Fischereder, S. Moscher, A. Schenk, R. Trattnig, M. Sezen, G. Mauthner, A. Pein, D. Meischler, K. Bartl, R. Saf, N. Bansal, S. A. Haque, F. Hofer, E. J. W. List and G. Trimmel, Adv. Energy Mater., 2011, 1, 1046-1050.

28 M. Arar, M. Gruber, M. Edler, W. Haas, F. Hofer, N. Bansal, L. X. Reynolds, S. A. Haque, K. Zojer, G. Trimmel and T. Rath, Nanotechnology, 2013, 24, 484005.

29 C. Krause, D. Scheunemann, J. Parisi and H. Borchert, J. Appl. Phys., 2015, 118, 205501.

30 Z. Liu, Y. Sun, J. Yuan, H. Wie, X. Huang, L. Han, W. Wang, H. Wang and W. Ma, Adv. Mater., 2013, 25, 5772-5778.

31 X. Du, Q. Zeng, G. Jin, F. Liu, T. Ji, Y. Yue, Y. Yang, H. Zhang and B. Yang, Small, 2017, 13, 1603771.

32 T. Rath and G. Trimmel, Hybrid Mater., 2014, 1, 15-36.

33 C. Fradler, T. Rath, S. Dunst, I. Letofsky-Papst, R. Saf, B. Kunert, F. Hofer, R. Resel and G. Trimmel, Sol. Energy Mater. Sol. Cells, 2014, 124, 117-125.

34 S. Mourdikoudis and L. M. Liz-Marzán, Chem. Mater., 2013, 25, 1465-1476.
35 W.-C. Huang, C.-H. Tseng, S.-H. Chang, H.-Y. Tuan, C.-C. Chiang, L.-M. Lyu and M. H. Huang, Langmuir, 2012, 28, 8496-8501.

36 A. Pein, M. Baghbanzadeh, T. Rath, W. Haas, E. Maier, H. Amenitsch, F. Hofer, C. O. Kappe and G. Trimmel, Inorg. Chem., 2011, 50, 193-200.

37 S. L. Castro, S. G. Bailey, R. P. Raffaelle, K. K. Banger and A. F. Hepp, J. Phys. Chem. B, 2004, 108, 12429-12435.

38 J. J. Nairn, P. J. Shapiro, B. Twamley, T. Pounds, R. von Wandruszka, T. R. Fletcher, M. Williams, C. Wang and M. G. Norton, Nano Lett., 2006, 6, 1218-1223.

39 D. Pan, D. Weng, X. Wang, Q. Xiao, W. Chen, C. Xu, Z. Yang and Y. Lu, Chem. Commun., 2009, 4221-4223.

40 M. Al-Shakban, P. D. Matthews, X. L. Zhong, I. VitoricaYrezabal, J. Raftery, D. J. Lewis and P. O'Brien, Dalton Trans., 2018, 47, 5304-5309.

41 D. P. Dutta and G. Sharma, Mater. Lett., 2006, 60, 2395-2398. 42 S. H. Lu, T. F. Chen, A. J. Wang, D. Zheng, Y. L. Li and Y. S. Wang, Mater. Sci. Eng., B, 2016, 203, 19-26.

43 A. Kharkwal, K. Jain, S. B. Tyagi, A. K. Singh, S. N. Sharma and M. Kharkwal, Colloid Polym. Sci., 2014, 292, 2913-2926.

44 A. Kharkwal, S. N. Sharma, K. Jain, L. Arora, P. Chawla, A. K. Singh and S. Chand, Colloid Polym. Sci., 2013, 291, 2607-2617.

45 C. Buchmaier, T. Rath, F. Pirolt, A.-C. Knall, P. Kaschnitz, O. Glatter, K. Wewerka, F. Hofer, B. Kunert, K. Krenn and G. Trimmel, RSC Adv., 2016, 6, 106120-106129.

46 O. Glatter, J. Appl. Crystallogr., 1980, 13, 7-11.

47 D. G. Calatayud, T. Jardiel, M. Rodríguez, M. Peiteado, D. Fernández-Hevia and A. C. Caballero, Ceram. Int., 2013, 39, 1195-1202.

48 D. So and G. Konstantatos, Chem. Mater., 2015, 27, 8424-8432.

49 G. Socrates, Infrared characteristic group frequencies: tables and charts, Wiley, 2nd edn, 1998.

50 N. Blouin, A. Michaud and M. Leclerc, Adv. Mater., 2007, 19, 2295-2300.

51 H. Zhong, S. S. Lo, T. Mirkovic, Y. Li, Y. Ding, Y. Li and G. D. Scholes, ACS Nano, 2010, 4, 5253-5262.

52 A.-C. Knall, A. O. F. Jones, B. Kunert, R. Resel, D. Reishofer, P. W. Zach, M. Kirkus, I. McCulloch and T. Rath, Monatsh. Chem., 2017, 148, 855-862.

53 M. Jäger, R. Trattnig, M. Postl, W. Haas, B. Kunert, R. Resel, F. Hofer, A. Klug, G. Trimmel and E. J. W. List, J. Polym. Sci., Part B: Polym. Phys., 2013, 51, 1400-1410. 